\title{
Using Visualisation to Test Historical Utopian Cities on a Modern Audience
}

\author{
Tessa Morrison \\ The School of Architecture and Built Environment \\ The University of Newcastle \\ NSW, 2308, Australia \\ tessa.morrison@newcastle.edu.au
}

\author{
Mark Rubin \\ School of Psychology \\ The University of Newcastle \\ NSW, 2308, Australia \\ mark.rubin@newcastle.edu.au
}

\begin{abstract}
At last year's EVA conference, a paper was presented entitled 'Utopian Cities from $15^{\text {th }}$ to $19^{\text {th }}$ Century Literature: A Philosophical Investigation through 3-D Visualisation.' This paper outlined a project that examines ten utopian cities from social reform literature. Each one of these works proposed a utopian community which was to be governed according to a particular political philosophy and outlined an architectural plan for the cities. These philosophies are considered to be important political philosophies of their respective eras and have subsequently made their mark in the history of ideas and politics. The central research question of this project is: does the architectural plan of the utopian cities with their the housing, communication systems, communal spaces, reflect the political philosophy of that city? To test this question four of the cities, two from the seventeenth century and two from the nineteenth century, were reconstructed using 3-D modelling program ArchiCAD and a survey was conducted on a modern audience. The survey used a series of images from the visually constructed cities. This paper considers the use of visualisation to test history and philosophy on a modern audience and whether such an approach can be considered successful.
\end{abstract}

Utopian cities. Urban planning. Visualisation.

\section{BACKGROUND}

Utopian cities have been discussed for over 2000 years since the time of Plato. Plato's emphasis was on the political aspects of the city. However, he did give an outline of the symmetrical ground plan (Plato 1981). The tradition of political philosophy and symmetrical utopian cities was reinforced in the Renaissance and continued on into the late nineteenth century. The descriptions of the cities became more and more detailed and were designed to enhance the political philosophies of the authors. Most of these cities were never built and remained only in literature. Nevertheless, they were extremely influential both politically and architecturally (Mumford 1962, Dixon 1998). This paper examines four utopian cities: two from the seventeenth century, Johann Valentin Andreae's Christianopolis (1619), and Tommaso Campanella's City of the Sun (1602), and two from the nineteenth century, Robert Owen's New Harmony (1817) and James Silk Buckingham's city of Victoria (1849).

Both seventeenth and nineteenth centuries were eras of dynamic change and societal crises. The seventeenth century was the era of the Enlightenment, new philosophies and the birth of science. However, this Enlightenment came at a cost, with a great deal of political and religious turmoil which resulted in catastrophic wars and social divisions (Outram 2013). Both Andreae's and Campanella's works resulted from the turmoil of the times. The plans of these cities were to protect citizens from external violence and disease, and to create a community that would enhance their lifestyle and create a spiritual society free from prejudice.

The nineteenth century had different reasons for creating utopian cities. The sciences and technologies that were such a revelation in the seventeenth and eighteenth centuries had created dramatic changes in the structure and employment of society. The Industrial Revolution, although beneficial to many, was detrimental to a large section of society, particularly the labouring classes (Williamson 2002). The machines that had been created in the first half of the eighteenth century were powered by water since the steam engine was in its infancy. Many small towns appeared in the middle of nowhere but they were situated near a water source. There were no established towns near many of these waterfalls and other water sources. There was a need to create towns around 
the mills and other industries many of which were built in haste and with little consideration to any urban plan or the community. Also people were forced to leave small village settlements where they made their living at cottage industries as large tracts of land were enclosed to create substantial farms. People flocked to the overcrowded and impoverished urban centres for both employment and housing (Langton 2000).

Owen's and Buckingham's proposed cities of New Harmony and Victoria were attempts to solve both the employment and housing problems. These towns were intended to be self-sufficient and sustainable. They offered protection from poverty, security, improvements to education, health and lifestyle.

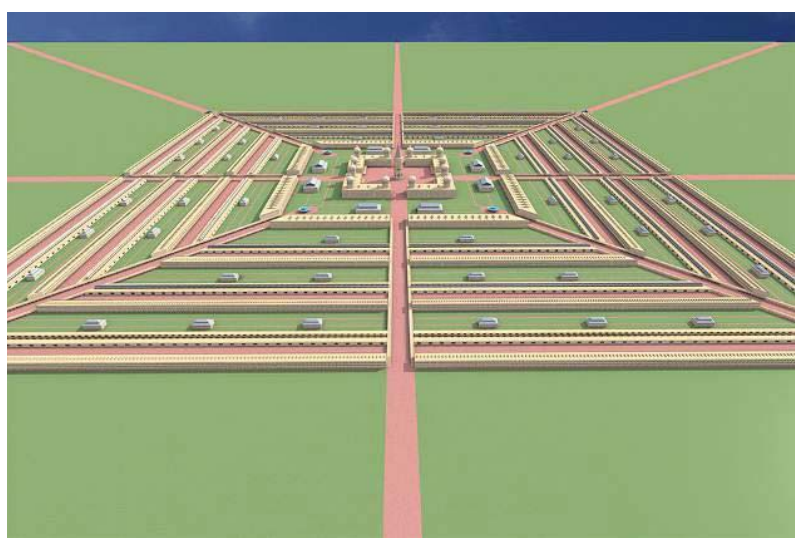

Figure 1: Reconstruction of Buckingham's Victoria

The four authors of these utopian works each propagated particular philosophies and their design for their city was intended to enhance their philosophy. Since they were never built it is difficult to ascertain whether the philosophy and the city design were complimentary. The reconstruction of these cities, using the 3-D architectural modelling program ArchiCAD is the first of its type.

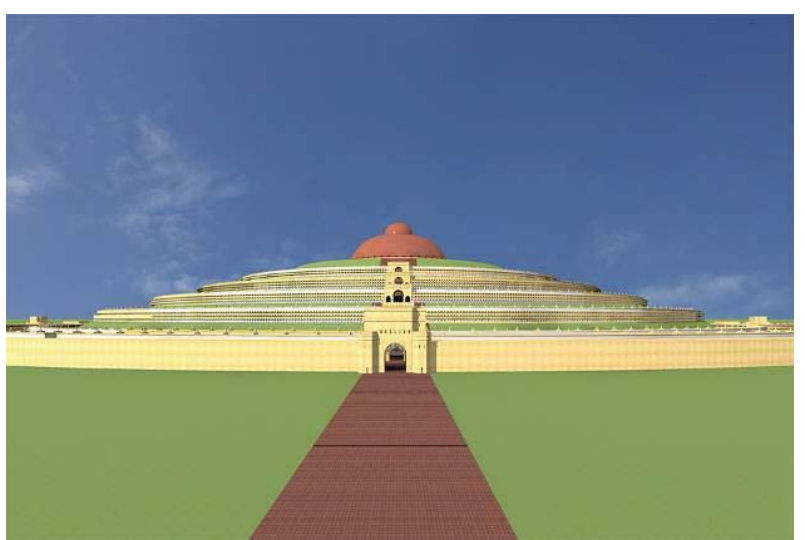

Figure 2: Reconstruction of the Campanella's city of the Sun

The survey conducted by the authors was intended to test whether the philosophies that were embedded into the cities are apparent to a modern audience.

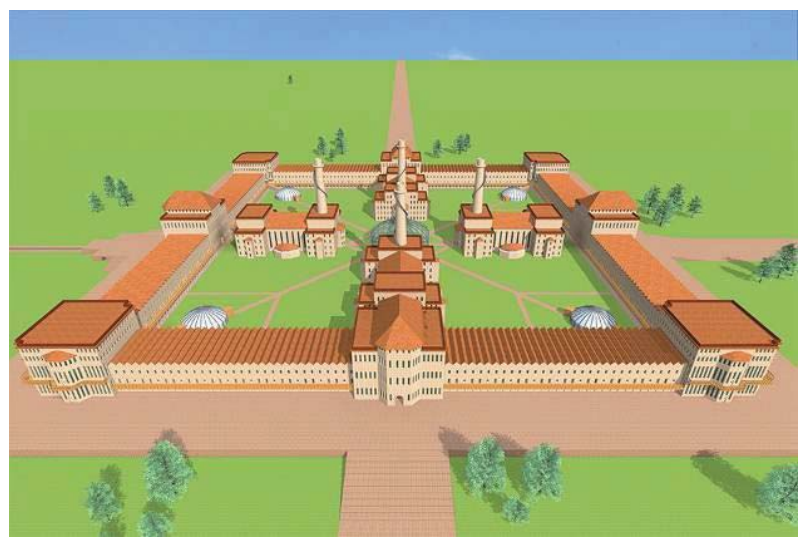

Figure 3: Reconstruction of Owen's New Harmony

\section{METHOD OF THE SURVEY}

\subsection{The participants of the survey}

The participants of the survey were recruited from an undergraduate psychology course at a large Australian university. Although data was collected from 196 participants, 37 withdrew early and did not complete the informed consent question at the end of the survey, and another 11 declined consent for the data to be used. The remaining 148 participants ( 37 male and 111 female), were aged between 18 and 38 years old. The majority of participants identified as Caucasian $(N=125)$, $11.51 \%$ consider themselves to be working class, $14.39 \%$ lower middle class $48.20 \%$ middle class, $25.18 \%$ upper middle class and $0.78 \%$ upper-class.

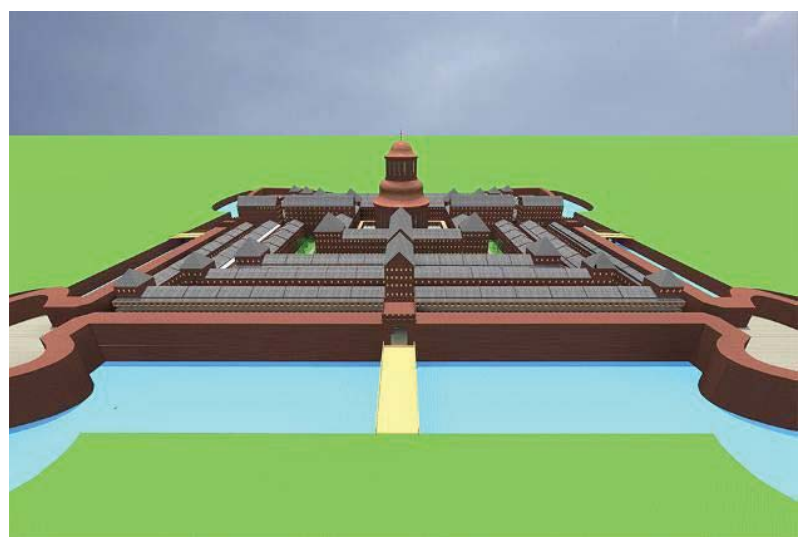

Figure 4: Reconstruction of Andreae's Christianopolis

\subsection{The procedure}

The study was presented using an online survey. Participants were asked to complete the survey in their own time, on their own, and in a quiet environment that did not contain any distractions. The study was entitled 'virtual walk around a historical city' and it was introduced to the 
participants as 'investigating people's evaluations of a historical city.' Participants viewed one of the four cities in a two and a half minute slide show that consisted of between 25 and 30 colour slides of the reconstruction each slide was presented for four seconds. The first slide was a map of the city so the participant would be able to anticipate the path through the city. Each slide showed a sequential view of the city from the perspective of a visitor who enters the city walks around inside it and then leaves the city.

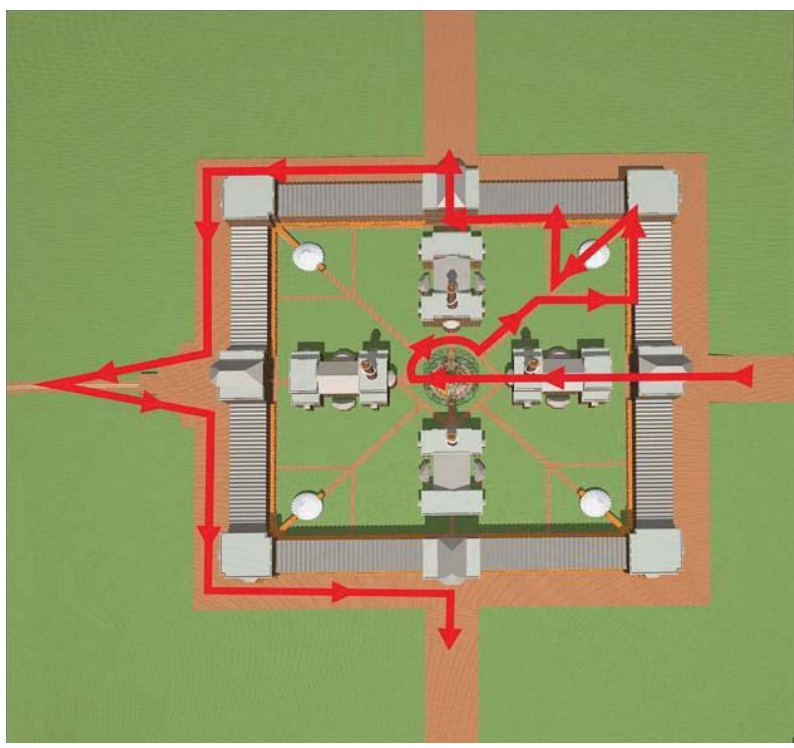

Figure 5: Map of New Harmony indicating the walk through the city

The decision to use slides instead of a fly through presentation was for two reasons. First, the file sizes of quality flythrough presentations would have been extremely large and would be slow to upload, which perhaps would have caused frustration to the participants and may have distract them from concentrating on the city. To have a fly through presentation incorporated into the survey would have meant that the quality of the visual experience would be a great deal lower, since a lower DPI would have had to been used. Second, the speed of the walk had to be taken into consideration. A flythrough of an entire city would have taken considerably longer and would be impossible to compress into two and a half minutes. So the selection of the slides was selected to not only highlight the features of the city but to reflect the ambulance of the city.

It was important to present the cities with consistent textures, tone, colour, shadows and daylight, so that all details were comparable. The cities light parameters were set at 11.00am, 15 April, Mediterranean, with a sun azimuth of 74.55 degrees and sun altitude $-\mathbf{3 7 . 1 3}$ degrees.

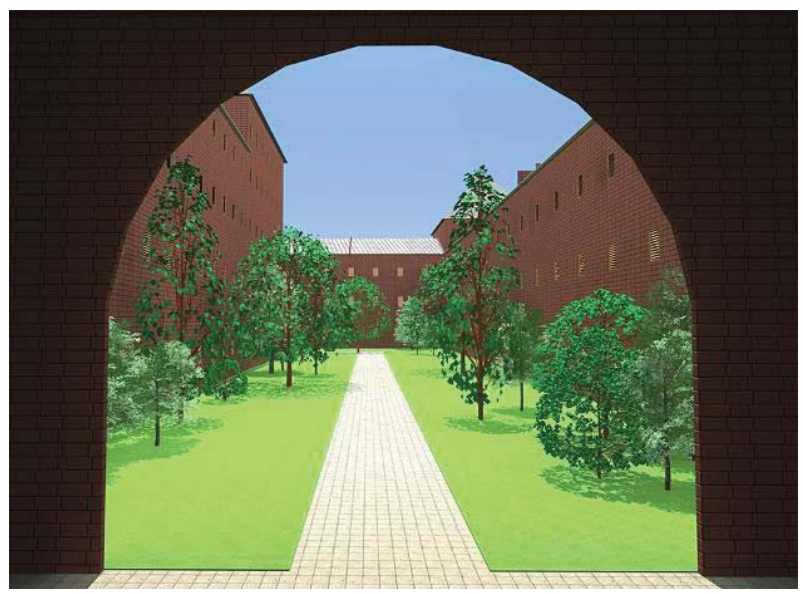

Figure 6: The open spaces of Christianopolis

The slideshows included audio narration that explained what participants were viewing at each stage of their tour. For example, part of the narration for New Harmony explained that:

This square city is built in brick. There is one main circuit, which consists of the domestic buildings, which surround the central courtyard. The city itself is on a raised platform 15 feet high. To enter the city you enter through a covered walkway, which goes through a tower of domestic buildings. Directly ahead is one of the four large communal buildings in the city. These buildings cater to the communal needs of the cities inhabitants and include dining and kitchen facilities. You walk through one of these buildings; in this building is a large dining room. The room has seven tall windows on each side, which provides natural light throughout the large room.

It was thought that the narration would increase participants' engagement with the task of viewing the city.

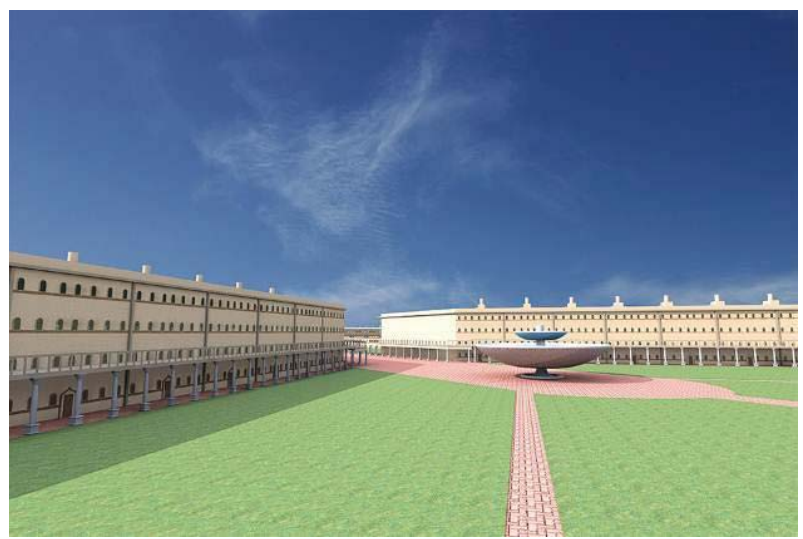

Figure 7: The open spaces of Victoria

The cities did not contain any people. If people had been included the first problem would be what era should these people represent? The era of the original design or the modern era? Either one would distract from the city. The former would 
make it possible for the participants to date the architecture which would carry preconceptions of the city with it and the latter would distract from the historic (but undated) character of the city. Although this empty city does represent an unnatural scene, the participants would be more focused on the city itself and the evaluations would be based on the experience of the city rather than the residents of the city.

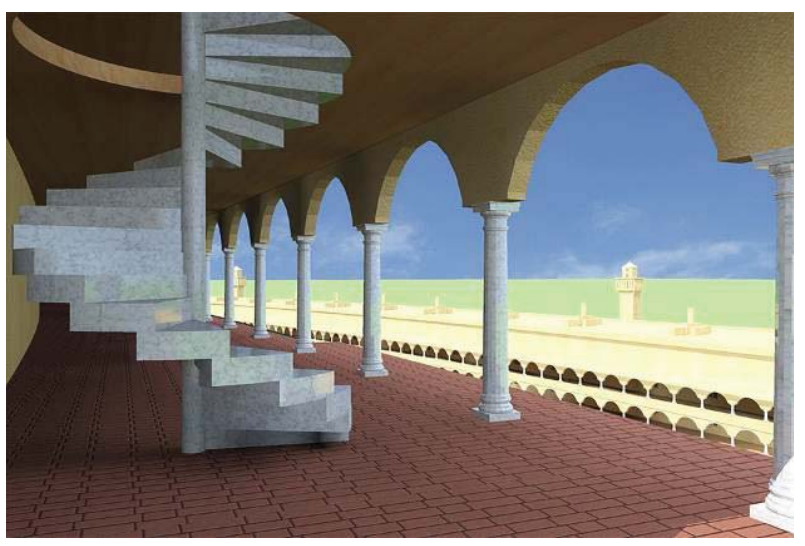

Figure 8: Walkway of a circuit of the Sun of the Sun

\subsection{The survey}

Although these cities are well known in utopian literature and are included in every assessment of utopian cities, they are better known for the political ideas behind them. The design features have never been previously examined and no prior research has been undertaken to investigate whether these cities' designs embody the political philosophy of the authors. The participants were asked to evaluate the city on a number of different dimensions. They were asked to indicate how much they agreed or disagreed with various statements about themselves, their personality, and the relationships with others. The questionnaire required participants to provide 108 responses, and the survey took about 20 minutes to complete.

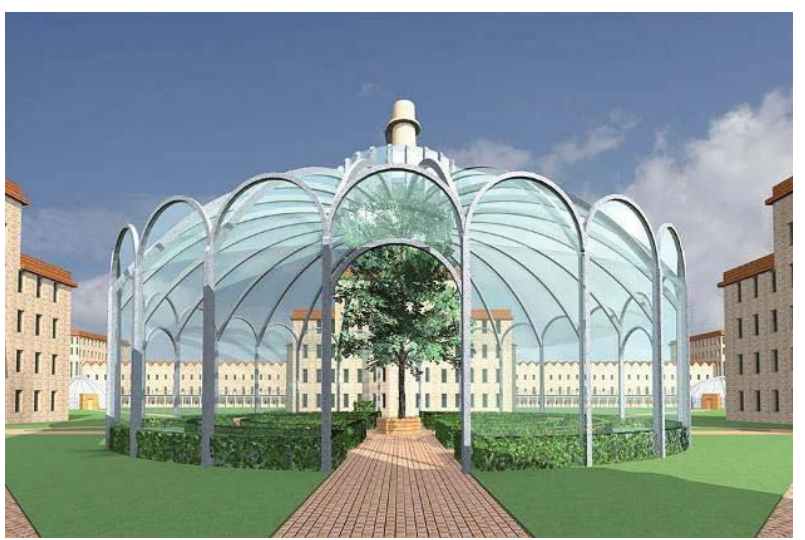

Figure 9: Conservatory at New Harmony
After viewing the walk of the city, the participants were asked to indicate how much they agreed or disagreed with various statements in four areas:

(i) How positive or negative they felt about the cities. For example, were the cities pleasant, imposing, impressive, liveable, enjoyable to walk around? How did these cities make them feel: happy, sad, anxious, elated, depressed?

(ii) How they perceived the architecture: examples of the questions are:

- 'I did not like the architecture of the city.'

- 'I enjoyed the open spaces of the city.'

- ' 'I did not enjoy walking around the city.'

- 'I felt very impressed by the city.'

- 'How easy do you think it is to get from one place to another in the city?'

- 'How ordered and organized did you find the city?'

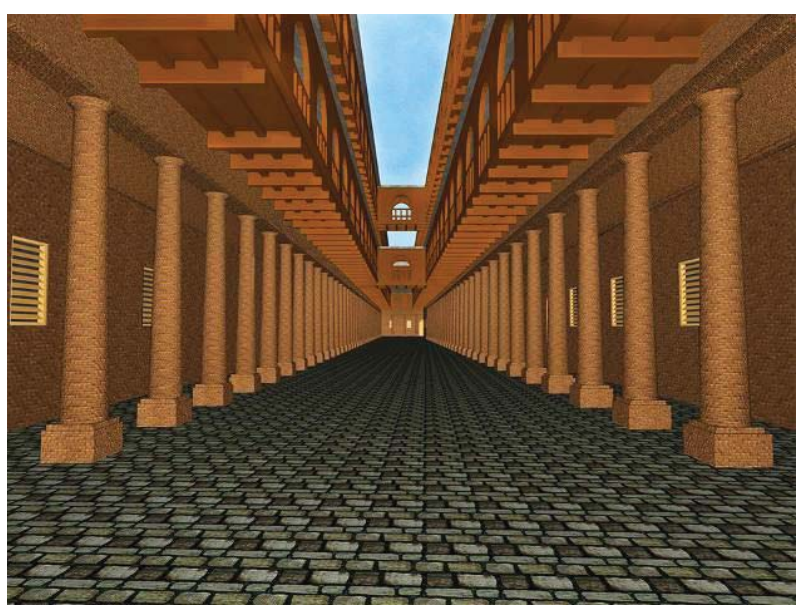

Figure 10: Domestic housing at Christianopolis

(iii) Their personal level of individualism and collectivism, for example:

- I would rather leave my group if I have to sacrifice my self-interest for the group

- I stick with my group even through difficulties.

- I don't support my group when they are wrong.

- I do things in my way regardless of what my group members expect me to do.

- I don't change my opinions in conformity with those of the majority.

- I think it is desirable for the members of my group to have the same opinions

(i), (ii), and (iii) were measured on a 7-point scale (ranging from 1 = strongly disagree to $7=$ strongly agree).

(iv) Demographic variables, which included age, gender, ethnicity, and social class. 


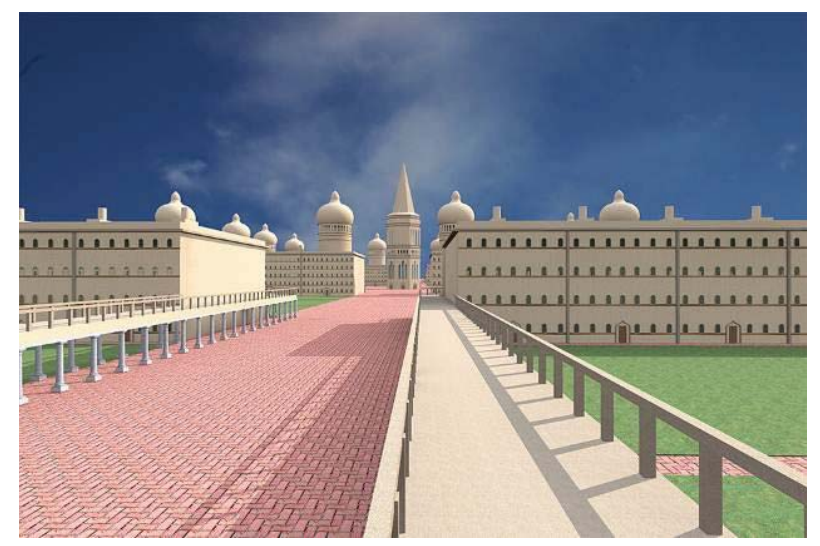

Figure 11: Walkways and looking towards the centre at Victoria

\subsection{The results of the survey}

The results of the survey are reported in detail in a forthcoming article (Rubin \& Morrison 2013). The overall analysis of the survey showed that people who reported a strong sense of self-responsibility (individualism) rated the cities as more liveable because they perceived them to be richer and better resourced. In contrast, people who reported a strong commitment to their social groups (collectivism) rated the cities as having a better environmental quality because they perceived them to (a) provide a greater potential for community and social life and (b) allow people to express themselves and be who they want to be. These results indicate that people's evaluations of cities are, to some extent, based on the degree to which the cities are perceived to enable the expression of individualist and collectivist values.

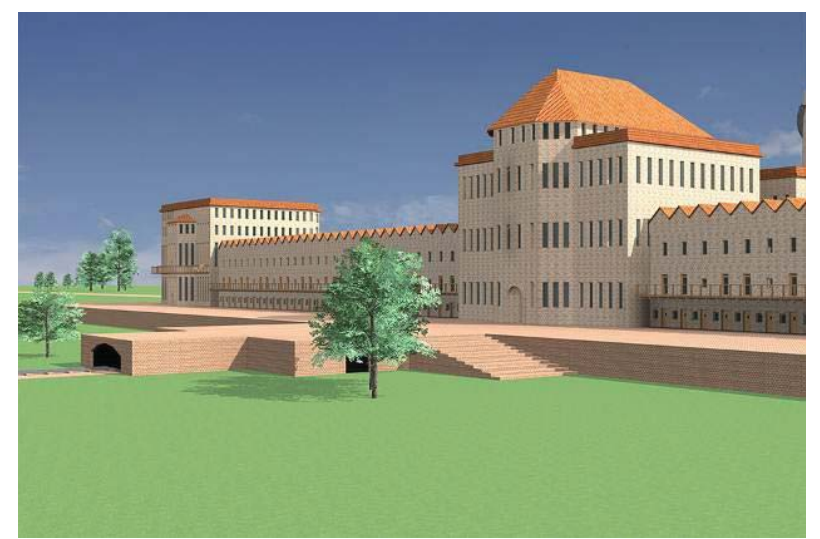

Figure 12: View of the residential block and underground railway tunnel at New Harmony

The survey also revealed that the participants of the survey disliked the architecture but indicated a very positive attitude and interest in the environmental quality and livability of the city, particularly safety, order and organisation, spaciousness and permeability or spatial planning. In short, the interest was in the desirable qualities of a city that were required by the authors of the utopian literature to promote their political philosophies.

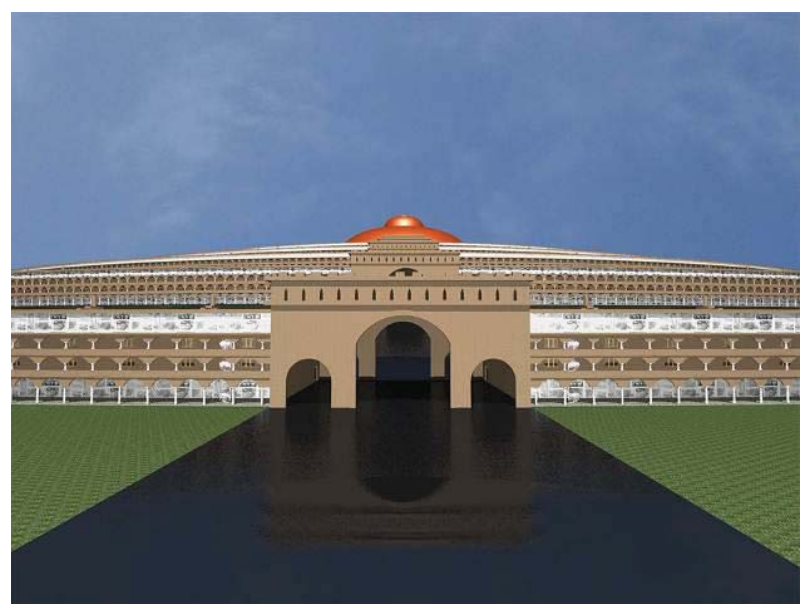

Figure 13: Residential circuit at the city of the Sun

\section{CONCLUSION}

\subsection{Why test historic urban planning on a modern audience?}

These four city designs were meant to have aesthetic values; the architectural details were carefully considered by all four authors. However, more importantly there were also meant to be conducive for the society that the political philosophies wish to support. All four cities were strongly concerned with environmental aspects of the city such as order, protection, community safety, spaciousness, mobility convenience and amenities. These environmental aspects are still relevant today in urban designs (Carmona et al. 2002). They form the basis of good urban planning and are recognised in many studies (Hillier et al. 1984).

The survey demonstrated that although the participants did not like the architecture, which they found to be repetitive and dull, they were interested in the environmental elements that constituted good urban design and which had been considered by these utopian authors, although not as elements of urban planning but as elements of good community. As virtual visitors to these historic utopian cities, the participants recognised design elements of urban planning from the seventeenth and nineteenth century that remain relevant to modern-day communities.

\subsection{Limitations of the survey}

In the present research, psychology students were asked to consider novel, historical, uninhabited, utopian cities in a virtual environment. A key strength of this approach was that it reduced the influence of participants' preconceived evaluations 


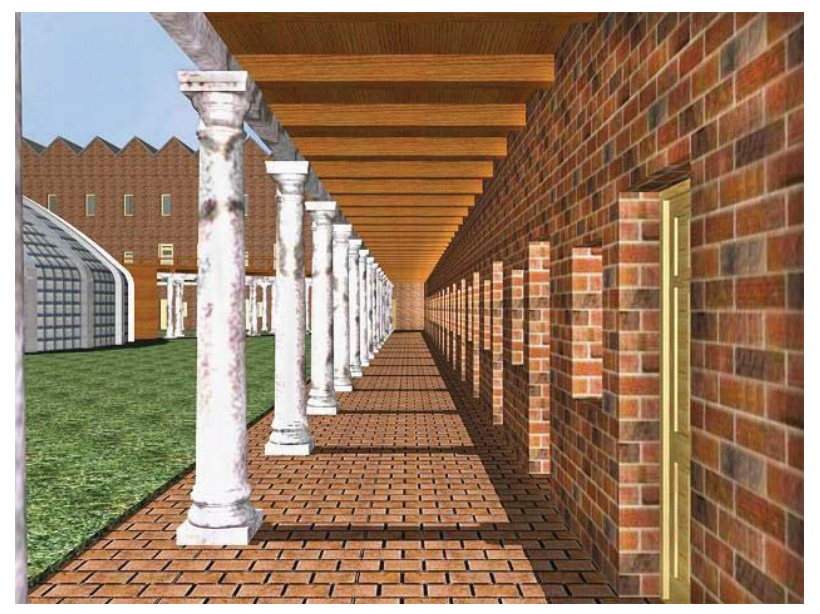

Figure 14: Walkway at New Harmony

of specific cities with which they were familiar on their evaluations of the city that they toured during the study. In addition, the absence of people on the streets of the city allowed participants to focus on the city itself and imagine what it might be like to live there rather than to have their evaluations affected by the actual degree of social life that occurred within the city.

Participants had no architectural or urban planning training: yet, they identified within a significant number of questions key elements of urban planning. Hence, the approach obtained relatively unbiased evaluations of cities, independent of other extraneous variables.

\subsection{Is visualisation a satisfactory method of testing and analysing historic urban planning?}

To the best knowledge of the authors, this approach to understanding historical designs of cities is unprecedented in the literature. The main aim of the project was to consider whether the architectural plan of the utopian cities with the housing, communication systems, and communal spaces would reflect the political philosophy of that city? The only way this could be tested was in a virtual environment.

These four cities from the seventeenth and the nineteenth century were created to solve distinct problems of their eras. There is also a difference in the political philosophies from these eras. Yet the cities they desired to perpetuate their philosophies had strong similarities. They were strongly orientated to community and were required to foster individuals that could interact with each other in a healthy, safe and secure environment - the essence of a utopian society.

By reconstructing these cities, it was possible to test their 'utopian' value. Although the architecture was considered boring, dated and found wanting, the ideals of good urban planning - which had not established in the seventeenth and nineteenth century - were embedded in their utopian plans.

Modern mathematical analysis of Space Syntax (Hillier et al. 1984), a series of 2D graphs and charts that reveal movement through the city was developed in the 1980s. This type of analysis makes it possible to compare the structure of the architectural space and its connectivity. Recently Isovist Fields have been developed which is a spatial analysis that uses 3-D digital models analyses space through given points of space. It measures 3-D immersion that is undertaken when a person walks within and fully experiences a space (Marriage et al. 2013, Ostwald et al. 2013). Both these mathematical models demonstrate the current interest in the spatial environment of urban design which has developed over the last 30 years. However, the political philosophy and the utopian designs of these seventeenth and nineteenth century unbuilt cities demonstrate that this current interest in spatial environmental factors of urban planning is in fact not so current, and these design elements are embedded into their cities which can be recognised by a modern audience.

\section{REFERENCES}

Andreae, J. V. (1999) Christianopolis. In: Thompson, E. H. (ed.) Christianopolis. Dordrecht: Kluwer Academic Publishers.

Buckingham, J. S. (1849) National Evils and Practical Remedies, with The Plan of a Model town, London, Peter Jackson, Son, \& Co.

Campanella, T. (1968) Campanella's City of the Sun. In: MORLEY, H. (ed.) Ideal Commonwealths. Washington: Kennikat Press.

Dixon, D. R. (1998) The Tessera of Antilia: Utopian Brotherhood and Secret Societies in the Early Seventeenth Century, Leiden, Boston and Koln, Brill.

Hillier, B. (1996) Space is the Machine : A Configurational Theory of Architecture Cambridge \& New York, Cambridge University Press.

Hillier, B. (2011) Is Architectural Form Meaningless? A Configurational Theory of Generic Meaning in Archecture, and its Limits. The Journal of Space Syntax, 2, 125-153.

Hillier, B., and Hanson, J. (1984) The Social Logic of Space, Cambridge, New York.

Langton, J. (2000) Proletarianization in the Industrial Revolution: Regionalism and Kinship in the Labour Markets of the British Coal Industry from the Seventeenth to the Nineteenth Centuries. Transactions of the Institute of British Geographers, $25,31-49$. 
Mumford, L. (1962) The Story of Utopia, New York, The Viking Press.

Ostwald, M. J., and Dawes, M. (2013) ProspectRefuge Patterns in Frank Lloyd Wright's Prairie Houses: Using Isovist Fields to Examine the Evidence. The Journal of Space Syntax 4, 136-56.

Outram, D. (2013) The Enlightenment, Cambridge, Cambridge University Press.

Owen, R. (1817) Report to the Committee of the Association for the Relief of the Manufacturing and Labouring Poor, London.
Plato (1974) Plato's Republic, Indianapolis:, Hackett Publishing Company.

Plato (1981) Timaeus and Critias, Hammondsworth, Penguin Books.

Rubin, M., and Morrison, T. (2013) Individual differences in individualism and collectivism predict ratings of city liveability and environmental quality. Unpublished manuscript, The University of Newcastle, Australia. 